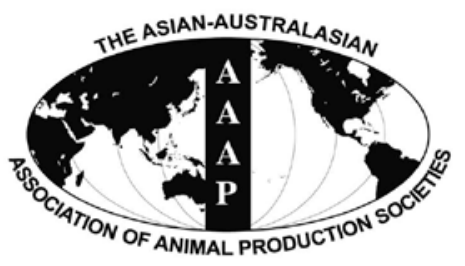

Asian-Aust. J. Anim. Sci.

Vol. 25, No. 1 : 22 - 27

January 2012

www.ajas.info

http://dx.doi.org/10.5713/ajas.2011.11084

\title{
Association of Length of Pregnancy with Other Reproductive Traits in Dairy Cattle
}

\author{
Zenon Nogalski* and Dariusz Piwczyński ${ }^{1}$ \\ University of Warmia and Mazury in Olsztyn, Department of Cattle Breeding and Milk Quality Evaluation, \\ Oczapowskiego 5, 10-719 Olsztyn, Poland
}

\begin{abstract}
The experiment involved observations of 2,514 Holstein-Friesian cows to determine the effects of environmental factors (cow's age, calving season, weight and sex of calves, housing system) and genetic factors on gestation length in dairy cattle and the correlation between gestation length and other reproductive traits (calving ease, stillbirth rates and placental expulsion). Genetic parameters were estimated based on the sires of calved cows (indirect effect) and the sires of live-born calves (direct effect). The following factors were found to contribute to prolonged gestation: increasing cow's age, male fetuses and growing fetus weight. Optimal gestation length was determined in the range of 275-277 days based on calving ease and stillbirth rates. The heritability of gestation length was estimated at $0.201-0.210$ by the direct effect and $0.055-0.073$ by the indirect effect. The resulting genetic correlations suggest that the efforts to optimize (prolong) gestation length could exert an adverse influence on the breeding value of bulls by increasing perinatal mortality and calving difficulty. The standard errors of the investigated parameters were relatively high, suggesting that any attempts to modify gestation length for the purpose of improving calving ease and reducing stillbirth rates should be introduced with great caution. (Key Words : Holstein-Friesian Breed, Calving Ease, Stillbirth Rates, Heritability, Genetic Correlations)
\end{abstract}

\section{INTRODUCTION}

Gestation length (GL), the period from effective fertilization until calving, is a reproductive trait that significantly affects cattle breeding and production. The cow's age is the key environmental factor influencing gestation length. Gestation length is shorter in heifers than in older cows (Przysucha and Grodzki, 2009). High temperatures in the summer speed up calving and shorten gestation length (McClintock et al., 2003). High milk yield prolongs gestation, as suggested by a positive genetic correlation between GL and milk production levels (Silva et al. 1992). Both longer and shorter gestation periods contribute to a higher number of stillbirths (Norman et al., 2009). GL values should be analyzed in conjunction with calving ease (CE), stillbirth rates (SB) and placental expulsion (PE) (Hansen et al., 2004; Przysucha and Grodzki,

\footnotetext{
* Corresponding Author : Z. Nogalski. Tel: +48-89-5233823, Fax: +48-89-5234413, E-mail: zena@uwm.edu.pl

${ }^{1}$ University of Technology and Life Sciences, Department of Genetics and General Animal Breeding, ul. Ks. Kordeckiego 20, 85-225 Bydgoszcz, Poland.
}

Received March 28, 2011; Accepted September 22, 2011
2009). Estimated heritability of GL based on the direct effect were determined in the range of $h^{2}=0.27-0.45$, whereas much lower values were reported based on the indirect effect (Hansen et al., 2004; Jamrozik et al., 2005; Norman et al. 2009). The above suggests that the main genetic factors affecting GL heritability are the fetus and, to a smaller extent, it's mother (Nogalski, 2003). The fetus' dominant effect on GL could be related to the induction of parturition. The fetal adrenal cortex secretes cortisol, increasing placental prostaglandin levels which initiate parturition (Stabenfeldt et al., 1992). Nadarajah et al. (1989) and Cervantes et al. (2009) reported significant genetic correlations between GL vs. CE and SB, whereas Hansen et al. (2004) observed a weak correlation between GL and other reproductive traits. Owing to the high significance of $\mathrm{CE}$ and SB values in the production of high-yielding dairy cattle, other traits contributing to the optimization of reproductive traits should also be studied.

The objective of this study was to determine the effect of selected factors on gestation length in dairy cattle and the correlations between gestation length and other reproductive traits. 


\section{MATERIALS AND METHODS}

The study investigated 2,514 Black-and-White Polish Holstein-Friesian cows kept in four cattle sheds, including two sheds in a tied-stall system and two sheds in a free-stall system. Gestation length (GL) was determined as the number of days between effective fertilization until calving. The animals were divided into five classes based on the reported GL values: up to 275 days, 275 to 277 days, 278 to 280 days, 281 to 283 days, and above 283 days. Based on the age factor, the cows were divided into primiparous, second-calf and third-calf females. Three calving seasons were identified: fall-winter (1 October to 31 January), winter-spring (1 February to 31 May) and summer (1 June to 30 September). The variability in calving ease was determined based on direct observations of calving ease (CE), stillbirth rates (SB) and placental expulsion (PE). Twin pregnancies were not taken into account. Calving ease was described in four categories: 1 - unassisted calving, 2 calving with little intervention (assisted by one person), 3 calving with considerable intervention (assisted by several persons), 4 - very difficult calving (hard pull) requiring veterinary intervention. Stillbirth values were assigned the following scores: 1 - born alive, survived the first $24 \mathrm{~h}$ after birth, 2 - dead at birth or died within the first $24 \mathrm{~h}$ after birth. Placental expulsion was classified as follows: 1 spontaneous expulsion within $12 \mathrm{~h}$ after birth, 2 spontaneous expulsion within $24 \mathrm{~h}$ after birth, 3 - placenta removed by a veterinarian.

Distribution (\%) of calving ease, stillbirths and placental expulsion in respect of investigated factors is presented in Table 2. Calf sex was described as: 1 - female calf, 2 - male calf. Calves were weighed directly after birth with the accuracy of $0.1 \mathrm{~kg}$. They were divided into four weight groups: up to $34 \mathrm{~kg}, 35$ to $37 \mathrm{~kg}, 38$ to $40 \mathrm{~kg}$, and above $40 \mathrm{~kg}$.

The effect of GL on CE was evaluated using the $x^{2}$ test. We wanted to examine whether the length of pregnancy has an impact on the share of dystocia in dairy cattle.

$$
x^{2}=\sum\left[\frac{f i-F i) 2}{F i}\right]
$$

where:

$f i=$ numbers obtained

$F i=$ expected number

The observed CE, SB and PE values were not characterized by normal distribution, therefore, they were subjected to probit transformation (Żuk, 1989) prior to statistical analysis.

All investigated traits, including gestation length, were subjected to explorative analysis with the involvement of multiple analysis of variance and the GLM procedure (SAS,
2008). A general linear model was developed in view of the key investigated traits as well as first-order interactions. The following classification model was used:

$$
\begin{aligned}
\mathrm{y}_{\mathrm{ijklmn}}= & \mu+\mathrm{H}_{\mathrm{i}}+\mathrm{W}_{\mathrm{j}}+\mathrm{S}_{\mathrm{k}}+\mathrm{U}_{\mathrm{l}}+\mathrm{P}_{\mathrm{m}} \\
& +(\mathrm{H} \times \mathrm{W})_{\mathrm{ij}}+. .+(\mathrm{U} \times \mathrm{P})_{\mathrm{lm}}+\mathrm{e}_{\mathrm{ijk} \mathrm{kmn}}
\end{aligned}
$$

where:

$\mathrm{y}_{\mathrm{ijklmn}}=$ phenotypic value of trait,

$\mu$ = general average,

$\mathrm{H}_{\mathrm{i}}=$ fixed herd effect $(\mathrm{i}=1, . ., 4)$,

$\mathrm{W}_{\mathrm{j}}=$ effect of successive calving $(\mathrm{j}=1, \ldots, 3)$,

$\mathrm{S}_{\mathrm{k}}=$ effect of calving season $(\mathrm{k}=1, . ., 3)$,

$\mathrm{U}_{\mathrm{l}}=$ effect of housing system $(\mathrm{l}=1,2)$,

$\mathrm{P}_{\mathrm{m}}=$ effect of calf sex $(\mathrm{m}=1,2)$,

$(\mathrm{H} \times \mathrm{W})_{\mathrm{ij}}, \ldots,(\mathrm{U} \times \mathrm{P})_{\mathrm{lm}},=$ interactions between factors,

$\mathrm{e}_{\mathrm{ijklmn}}=$ random error.

The genetic parameters of gestation length and reproductive traits were estimated using Gibbs sampling method and the sire model. The components of (co-)variance were determined with the involvement of THRGIBBS1F90 (Tsuruta and Misztal, 2006) software and bivariate linear-threshold models. GL was an obligatory component in bivariate models, and the second trait was one of the investigated reproductive attributes: SB, CE and PE. The components of (co-)variance were estimated by Gibbs sampling to generate 50,000 samples, of which 10,000 were representative of the burn-in period. The number of rejected initial samples was computed with the use of POSTGIBBS1F90 (Tsuruta and Misztal, 2006) application. The results produced by neighbor samples were correlated (auto-correlated), and genetic parameters were determined based on data for every 100th sample. Standard errors of (co-)variance components were calculated as standard deviation of component values produced by successive samples.

Other statistical sources of variability were determined in the GLM procedure, subject to the analyzed dependent variable, therefore, varied linear models were applied:

$$
\begin{aligned}
& \text { GL: } y=X_{W} \beta_{W}+X_{S} \beta_{S}+X_{P} \beta_{P}+Z_{s} s+e \\
& \text { SB: } 1=X_{U} \beta_{U}+X_{P} \beta_{P}+Z_{s} s+e \\
& \text { CE: } 1=X_{H} \beta_{H}+X_{W} \beta_{W}+X_{U} \beta_{U}+X_{P} \beta_{P}+Z_{s} s+e \\
& \text { PE: } 1=X_{H} \beta_{H}+X_{W} \beta_{W}+X_{S} \beta_{S}+X_{P} \beta_{P}+Z_{s} s+e
\end{aligned}
$$

$\mathrm{y}=\mathrm{n} \times 1$ observation vector; $\mathrm{l}=$ vector of liabilities;

$\beta_{\mathrm{H}}, \beta_{\mathrm{W}}, \beta_{\mathrm{S}}, \beta_{\mathrm{U}}, \beta_{\mathrm{P}}=$ fixed effect vectors: herd $\left(\mathrm{p}_{\mathrm{H}} \times 1\right)$, successive calving $\left(\mathrm{p}_{\mathrm{W}} \times 1\right)$, calving season $\left(\mathrm{p}_{\mathrm{s}} \times 1\right)$, housing system $\left(p_{U} \times 1\right)$, calf sex $\left(p_{P} \times 1\right)$; 
$\mathrm{s}=\mathrm{q} \times 1$ vector of random additive genetic sire effects;

$X_{H}, X_{W}, X_{S}, X_{U}, X_{P}=$ incidence matrices for fixed effects: herd $\left(n \times p_{H}\right)$, successive calving $\left(n \times p_{W}\right)$, calving season $\left(n \times p_{s}\right)$, housing system $\left(n \times p_{U}\right)$, calf sex $\left(n \times p_{P}\right)$;

$\mathrm{Z}_{\mathrm{s}}=\mathrm{n} \times \mathrm{q}$ incidence matrix for random additive genetic sire effects;

$\mathrm{e}=\mathrm{n} \times 1$ vector of random errors.

It was assumed that the liabilities conditional on all of the effects were independent and normally distributed.

The studied population's genetic parameters were determined using the following formula:

$$
\begin{aligned}
& \text { Heritability } h^{2}=\frac{4 \times \sigma_{\mathrm{S}}^{2}}{\sigma_{\mathrm{S}}^{2}+\sigma_{\mathrm{E}}^{2}} \text {, } \\
& \text { genetic correlation } \mathrm{r}_{\mathrm{g}}=\frac{\operatorname{cov}_{\mathrm{S}}}{\sqrt{\sigma_{\mathrm{S}_{1}}^{2} \times \sigma_{\mathrm{S}_{2}}^{2}}}, \\
& \text { phenotypic correlation } \quad r_{\mathrm{p}}=\frac{\operatorname{cov}_{\mathrm{S}}+\operatorname{cov}_{\mathrm{E}}}{\sqrt{\left(\sigma_{\mathrm{S}_{1}}^{2}+\sigma_{\mathrm{E}_{1}}^{2}\right)\left(\sigma_{\mathrm{S}_{2}}^{2}+\sigma_{\mathrm{E}_{2}}^{2}\right)}}
\end{aligned}
$$

where, $\sigma_{S}^{2}=$ additive genetic sire variance, $\sigma_{E}^{2}=$ error variance, where: $\operatorname{cov}_{\mathrm{s}}=$ genetic sire covariance.

Genetic parameters were estimated in two replications. At the first stage, 47 half-sib groups were created based on the sires of calved cows. In the second step, 24 half-sib groups were created in view of the sires mated to cows. The minimum size of a half-sib group was 15 individuals.

\section{RESULTS AND DISCUSSION}

The average gestation length was $279.1( \pm 4.79)$ days (Table 1), and was shorter than determined for Holstein cattle by Nadarajah et al. (1989) 281.3 days, Silva et al. (1992) 280 days, and Norman et al. (2009) 281.6 days. In a study by Hansen et al. (2004), the average gestation length
Table 1. Statistical characteristic for investigated traits

\begin{tabular}{lrcc}
\hline Variable & Mean & SD & Skewness \\
\hline Gestation lenght (d) & 279.54 & 4.79 & -0.029 \\
Calving ease & 1.60 & 0.88 & 1.36 \\
Stillbirths & 1.06 & 0.24 & 3.61 \\
Placental expulsion & 1.47 & 0.72 & 1.17 \\
\hline
\end{tabular}

in Danish Holstein cows was 278.5 days. Johanson and Berger (2003) reported average GL values in American HF cattle at 277.9 days. The gestation length of Guernsey, Holstein and Jersey cows in several Florida-based farms increased by four days on average over a period of 50 years. According to the authors Silva et al. (1992), this increase could be attributed to a steep rise in production levels. Shorter gestation was noted in the summer months, and these findings are consistent with the results of previous research which validated the effect of higher temperature and dietary changes on shorter GL (Hansen et al., 2004; Przysucha and Grodzki, 2009). In this study, a longer gestation period was observed in respect of older cows (Table 3). There was a significant difference between the first and the third calving, at one day on average. In a study analyzing only primiparous cows, Hansen et al. (2004) reported a difference of 3.5 days between heifers calved at the age of 22 and 36 months. In this study, the increase in calf weight significantly contributed to a rise in GL values. In the group of the heaviest calves ( $>40 \mathrm{~kg}$ ), GL was 3.9 days longer on average in comparison with the group of the lightest calves ( $\leq 34 \mathrm{~kg}$ ). Nadarajah et al. (1989) reported a difference of 3.7 days between cows with large and small fetuses. In this study, GL values were also significantly affected by the sex of the fetus, and they were 1.8 days longer for male fetuses. According to Silva et al. (1992) and Hansen et al. (2004), GL was 1.1 days longer for male calves.

Gestation length increased with the degree of calving difficulty (Table 4). Difficult and very difficult calvings

\begin{tabular}{|c|c|c|c|c|c|c|c|c|c|c|}
\hline \multirow{2}{*}{ Trait } & \multirow{2}{*}{ Level } & \multicolumn{4}{|c|}{ Calving ease } & \multicolumn{2}{|c|}{ Stillbirths } & \multicolumn{3}{|c|}{ Placental expulsion } \\
\hline & & 1 & 2 & 3 & 4 & 1 & 2 & 1 & 2 & 3 \\
\hline \multirow[t]{3}{*}{ Calving season } & Fall-winter & 66.67 & 21.11 & 8.89 & 3.33 & 95.33 & 4.67 & 70.44 & 19.11 & 10.44 \\
\hline & Winter-spirng & 55.51 & 24.25 & 13.43 & 6.81 & 92.99 & 7.01 & 62.53 & 22.04 & 15.43 \\
\hline & Summer & 62.66 & 24.03 & 7.14 & 6.17 & 92.53 & 7.47 & 64.29 & 22.73 & 12.99 \\
\hline \multirow[t]{3}{*}{ Successive calving } & First & 45.25 & 30.28 & 15.85 & 8.63 & 91.90 & 8.10 & 66.73 & 25.00 & 8.27 \\
\hline & Second & 68.88 & 20.82 & 7.09 & 3.20 & 94.51 & 5.49 & 65.90 & 17.39 & 16.70 \\
\hline & Third & 84.13 & 10.71 & 3.17 & 1.98 & 96.43 & 3.57 & 63.49 & 19.05 & 17.46 \\
\hline \multirow[t]{2}{*}{ Calf sex } & 1 (heifer calves) & 63.34 & 23.99 & 8.95 & 3.72 & 95.61 & 4.39 & 70.10 & 21.28 & 8.61 \\
\hline & 2 (bull calves) & 59.40 & 22.26 & 11.43 & 6.92 & 92.03 & 7.97 & 61.95 & 21.05 & 16.99 \\
\hline \multirow[t]{2}{*}{ Husbandry system } & 1 (tie-stall) & 54.82 & 26.76 & 11.37 & 7.05 & 92.23 & 7.77 & 70.36 & 19.57 & 10.07 \\
\hline & 2 (free-stall) & 69.22 & 18.51 & 8.90 & 3.38 & 95.55 & 4.45 & 60.14 & 23.13 & 16.73 \\
\hline
\end{tabular}
were characterized by a significant increase in GL values. A

Table 2. Distribution (\%) of calving ease, stillbirths and placental expulsion in respect of investigated factors 
Table 3. Least square means (LSM) of gestation length subject to calving season, calving number, calf weight and sex and housing system

\begin{tabular}{|c|c|c|c|}
\hline \multirow{2}{*}{ Specification } & \multicolumn{3}{|c|}{ Gestation length (d) } \\
\hline & $\mathrm{n}$ & LSM & SD \\
\hline \multicolumn{4}{|l|}{ Calving season } \\
\hline $\begin{array}{l}\text { Fall-winter } \\
\text { (1 October-31 January) }\end{array}$ & 900 & 279.1 & 4.65 \\
\hline $\begin{array}{l}\text { Winter-spring } \\
\text { (1 February-31 May) }\end{array}$ & 998 & 279.3 & 4.84 \\
\hline $\begin{array}{l}\text { Summer } \\
\text { (1 June-30 September) }\end{array}$ & 616 & 278.5 & 4.88 \\
\hline \multicolumn{4}{|l|}{ Successive calving } \\
\hline First & 1,136 & $278.6^{\mathrm{a}}$ & 4.89 \\
\hline Second & 874 & 279.3 & 4.74 \\
\hline Third & 504 & $279.6^{\mathrm{b}}$ & 4.55 \\
\hline \multicolumn{4}{|l|}{ Calf weight (kg) } \\
\hline$\leq 34$ & 626 & $278.0^{\mathrm{A}}$ & 4.37 \\
\hline $35-37$ & 670 & $279.2^{\mathrm{B}}$ & 4.28 \\
\hline $38-40$ & 558 & $280.7^{C}$ & 4.60 \\
\hline$>40$ & 300 & $281.9^{\mathrm{D}}$ & 4.72 \\
\hline \multicolumn{4}{|l|}{ Calf sex } \\
\hline Heifer calves & 1,184 & $278.1^{\mathrm{A}}$ & 4.39 \\
\hline Bull calves & 1,330 & $279.9^{\mathrm{B}}$ & 4.97 \\
\hline \multicolumn{4}{|l|}{ Housing system } \\
\hline Tie-stall & 1,390 & 279.0 & 4.72 \\
\hline Free-stall & 1,124 & 279.1 & 4.87 \\
\hline
\end{tabular}

Values followed by different letters in columns within factors differ significantly: capital letters $\mathrm{p} \leq 0.01$, small letters $\mathrm{p} \leq 0.05$.

significant correlation between GL and CE was demonstrated. Difficult and very difficult calvings that required veterinary assistance had a $15.67 \%$ share of all births. The highest share of difficult and very difficult calvings was reported in the group where GL exceeded 283 days, whereas the easiest calvings were observed in the group of cows whose GL ranged between 275 and 277 days. In a study by Cervantes et al. (2009), the GL of cows experiencing calving difficulties was 2.1 longer in comparison with cows that calved without assistance. Philipsson (1976) demonstrated a correlation between difficult calving and higher GL values in Swedish Friesian heifers.

Both prolonged and shortened gestation contributed to a significant increase in the number of stillbirths (Figure 1). The lowest SB rate (3.23\%) was observed in respect of GL values in the range of 275-277 days, whereas the share of calves that were born dead and died within $24 \mathrm{~h}$ after birth increased three-fold (to 10.48\%) when GL exceeded 283 days. Johanson and Berger (2003) and Philipsson (1976) reported a non-linear correlation between GL and SB. In this study, optimal gestation length in Holstein cows was determined in the range of 275-277 days based on calving ease and stillbirth values. In a study evaluating more than 4,000 Friesian cows characterized by average gestation length of 278.7 days, Johanson and Berger (2003) found that the optimal GL that minimized the risk of SB was 282 days. Deviations from the optimal GL value led to a significant increase in SB rates. According to Norman et al. (2011), average GL values optimized lifetime productivity, calving ease, stillbirth rates and calving-to-first-service interval.

In the discussed experiment, genetic parameters were estimated with the use of Gibbs sampling and bivariate linear-threshold models. A similar approach was adopted by Lee et al. (2002), Ramirez-Valverde et al. (2001), Varona et al. (1999) who investigated the adequacy of threshold-linear models for estimating breeding value based on calving ease, birth weight and gestation length. The above authors concluded that linear-linear models and threshold-linear models produced a similar sequence of breeding values for birth weight and gestation length. A lower correlation was determined with regard to calving ease (threshold trait). Threshold-linear models delivered more accurate estimations than linear- linear models.

The heritability of gestation length that accounted for direct sire of fetus effects varied in the range of 0.201-0.210 (Table 6). Heritability values determined in view of indirect maternal effects were visibly lower at 0.054-0.073 (Table 5) GL heritability indicators reported in this study were generally lower than the values reported by other authors (Hansen et al., 2004; Crews, 2006; Norman et al., 2009; Johanson et al., 2011).

The results of this study as well as the cited authors' findings were characterized by significant variance which

Table 4. Calving ease vs. gestation length $\left(x^{2}=35.1 ; \mathrm{p} \leq 0.01\right)$

\begin{tabular}{|c|c|c|c|c|c|c|c|c|c|c|}
\hline \multirow{3}{*}{ Calving ease } & \multicolumn{10}{|c|}{ Gestation length (d) } \\
\hline & \multicolumn{2}{|c|}{$<275$} & \multicolumn{2}{|c|}{$275-277$} & \multicolumn{2}{|c|}{$278-280$} & \multicolumn{2}{|c|}{$281-283$} & \multicolumn{2}{|c|}{$>283$} \\
\hline & $\mathrm{n}$ & $\%$ & $\mathrm{n}$ & $\%$ & $\mathrm{n}$ & $\%$ & $\mathrm{n}$ & $\%$ & $\mathrm{n}$ & $\%$ \\
\hline Unassisted & $254^{\mathrm{A}}$ & 55.95 & $408^{\mathrm{B}}$ & 73.12 & $344^{\mathrm{B}}$ & 66.70 & $328^{\mathrm{B}}$ & 62.12 & $234^{\mathrm{A}}$ & 51.09 \\
\hline Little intervention & $134^{\mathrm{a}}$ & 29.52 & $88^{\mathrm{b}}$ & 15.77 & $90^{\mathrm{b}}$ & 22.87 & $122^{\mathrm{a}}$ & 23.11 & $118^{\mathrm{a}}$ & 25.76 \\
\hline Difficult & 44 & 9.69 & 38 & 6.81 & 54 & 10.47 & 46 & 8.71 & 76 & 16.59 \\
\hline Very difficult & 22 & 4.85 & 24 & 4.30 & 28 & 5.43 & 32 & 6.06 & 30 & 6.55 \\
\hline
\end{tabular}

Values followed by different letters in rows differ significantly: capital letters $\mathrm{p} \leq 0.01$; small letters $\mathrm{p} \leq 0.05$. 


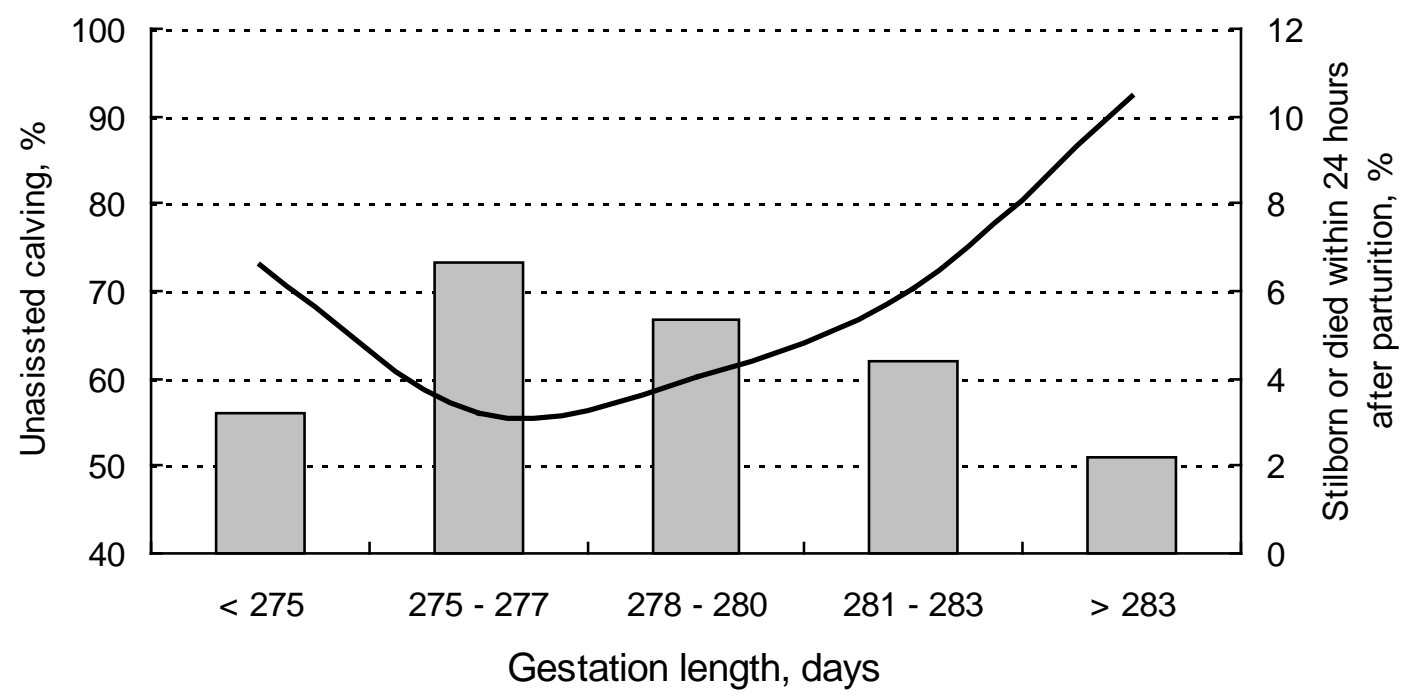

$\square$ unasissted calving — - stillborn or died within 24 hours after parturition

Figure 1. Gestation length vs. perinatal mortality and unassisted calving.

can be attributed to numerous factors, including the classification model (linear or threshold), type of random effects, influence of breed or successive lactation (Hansen et al., 2004; Crews 2006; Cervantes et al., 2009; Norman et al., 2009; Johanson et al., 2011).

The type of random effects in the classification model had a significant influence on the estimated heritability indicators as regards calving ease (Tables 5 and 6). When the random effect of sires of calved cows was taken into account, stillbirth heritability increased two-fold, whereas the heritability of placental expulsion was reduced more than three-fold, and the heritability of calving ease decreased more than two-fold.

The model accounting for the random effect of sires of calved cows demonstrates moderate positive genetic correlations between GL vs. SB and CE (Table 5). The genetic optimization of gestation length could have a negative influence on the breeding value of bulls by increasing stillbirth frequency and calving difficulty. The use of a classification model accounting for the sire of calf model produced correlations between GL vs. stillbirth rates and calving ease that were characterized by an identical pattern but lower strength (Table 6). Similar genetic correlations (direct effect) between gestation length vs. stillbirth rates (0.18) and calving difficulty (0.38) were reported by Hansen et al. (2004) with the use of a linearthreshold model. Subject to the type of random effect, genetic correlations with a different sign were reported for correlations between GL and placental expulsion. A negative correlation was determined for the random effect of sires of calved cows, while a positive correlation was reported for the effect of sires of live-born calves.

The coefficients of all phenotypic correlations between gestation length and calving ease were positive but low. The

Table 5. Heritability, genetic and phenotypic (SE) correlation between gestation length and calving ease subject to indirect sire effects

\begin{tabular}{lcccc}
\hline Parameter & Gestation length & Stillbirths & Placental expulsion & Calving ease \\
\hline Heritability & $0.054-0.073(0.032)$ & $0.420(0.157)$ & $0.155(0.067)$ & $0.211(0.085)$ \\
Genetic correlation & - & $0.555(0.321)$ & $-0.340(0.415)$ & $0.625(0.294)$ \\
Phenotypic correlation & - & $0.088(0.051)$ & $0.040(0.025)$ & $0.108(0.030)$ \\
\hline
\end{tabular}

() standard deviation is shown in brackets.

Table 6. Heritability, genetic and phenotypic (SE) correlation between gestation length and calving ease subject to direct sire effects

\begin{tabular}{lcccc}
\hline Parameter & Gestation length & Stillbirths & Placental expulsion & Calving ease \\
\hline Heritability & $0.201-0.210(0.062)$ & $0.195(0.099)$ & $0.560(0.182)$ & $0.552(0.169)$ \\
Genetic correlation & - & $0.179(0.453)$ & $0.149(0.244)$ & $0.242(0.161)$ \\
Phenotypic correlation & - & $0.078(0.044)$ & $0.046(0.029)$ & $0.113(0.032)$ \\
\hline
\end{tabular}

() standard deviation is shown in brackets. 
above suggests that prolonged gestation resulted in greater calving difficulty, higher stillbirth rates and longer placenta expulsion time.

An analysis of standard deviations of the investigated parameters revealed relatively high values (Tables 5 and 6). For this reason, modifications of gestation length should be introduced with great caution during attempts to improve calving ease and reduce stillbirth rates.

\section{CONCLUSIONS}

The following factors contributed to prolonged gestation in Holstein-Friesian cows: increasing cow's age, male fetuses and growing fetus weight. Optimal gestation length was determined in the range of 275-277 days based on calving ease and stillbirth values. In view of direct sire of fetus effects, GL heritability was found to be four-fold higher in comparison with heritability values produced by indirect maternal effects, the model accounting for the random effect of sires of calved cows demonstrated moderate positive genetic correlations between GL vs. SB and CE. The above suggests that genetic optimization of gestation length could have a negative influence on the breeding value of bulls by increasing stillbirth frequency and calving difficulty. The use of a classification model accounting for the sire of calf model produced correlations between GL vs. SB and CE that were characterized by an identical pattern but lower strength. The investigated parameters were marked by relatively high standard deviations, implying that GL modifications should be introduced with great caution during attempts to improve $\mathrm{CE}$ and SB values.

\section{REFERENCES}

Cervantes, J., J. P. Gutiérrez, I. Fernández and F. Goyache. 2009. Genetic relationships among calving ease, gestation length, and calf survival to weaning in the Asturiana de los Valles beef cattle breed. J. Anim. Sci. (serial online). 1-22. Available from www.http://jas.fass.org (accessed Sep 11, 2010)

Crews, D. H. 2006. Age of dam and sex of calf adjustments and genetic parameters for gestation length in Charolais cattle. J. Anim. Sci. 84:25-31.

Hansen, M., M. S. Lund, J. Pedersen and L. G. Christensen. 2004. Gestation length in Danish Holsteins has weak genetic associations with stillbirth, calving difficulty, and calf size. Livest. Prod. Sci. 91:23-33.

Johanson, J. M. and P. J. Berger. 2003. Birth weight as a predictor of calving ease and perinatal mortality in Holstein cattle. J. Dairy Sci. 86:3745-3755.
Johanson, J. M., P. J. Berger, S. Tsuruta and I. Misztal. 2011. Bayesian threshold-linear model evaluation of perinatal mortality, dystocia, birth weight, and gestation length in a Holstein herd. J. Dairy Sci. 94:450-460.

Jamrozik, J., J. Fatehi, G. I. Kistemaker and Schaeffer. 2005. Estimates of genetic parameters for Canadian Holstein female reproduction traits. J. Dairy Sci. 88:2199-2208.

Lee, D., I. Misztal, J. K. Bertrand and R. Rekaya. 2002. National evaluation for calving ease, gestation length and birth weight by linear and threshold model methodologies. J. Appl. Genet. 43:209-216.

McClintock, K. Beard A. Gilmour and Goddard. 2003. Relationships between calving traits in heifers and mature cows in Australia. Interbull Bulletin 31:102-106.

Nadarajah, K., E. B. Burnside and L. R. Schaeffer. 1989. Factors affecting gestation length in Ontario Holsteins. Can. J. Anim. Sci. 69:1083-1086.

Nogalski, Z. 2003. Relations between the course of parturition, body weights and measurements of Holstein-Friesian calves. Czech J. Anim. Sci. 48:51-61.

Norman, H. D., J. R. Wright, M. T. Kuhn, S. M. Hubbard, J. B. Cole and P. M. VanRaden. 2009. Genetic and environmental factors that affect gestation length in dairy cattle. J. Dairy Sci. 92:2259-2269.

Norman, H. D., J. R. Wright and R. H. Miller. 2011. Potential consequences of selection to change gestation length on performance of Holstein cows. J. Dairy Sci. 94:1005-1010.

Philipsson, J. 1976. Studies on calving difficulty, stillbirth and associated factors in Swedish cattle breeds. III. Genetic parameters. Acta Agric. Scand. 26:211-220.

Przysucha, T. and H. Grodzki. 2009. The influence of selected factors on beef breed cows pregnancy length (in Polish). Rocz. Nauk. Pol. Tow. Zoot. 5:65-72.

Ramirez-Valverde, R., I. Misztal and J. K. Bertrand. 2001. Comparison of threshold vs. linear and animal vs. sire models for predicting direct and maternal genetic effects on calving difficulty in beef cattle. J. Anim. Sci. 79:333-338.

SAS Institute Inc. 2008. SAS/STAT ${ }^{\circledR} 9.2$ User's Guide. Cary, NC: SAS Institute Inc.

Silva, H. M., C. J. Wilcox, W. W. Thatcher, R. B. Becker and D. Morse. 1992. Factors affecting days open, gestation length, and calving interval in Florida dairy cattle. J. Dairy Sci. 75: 288-293.

Stabenfeldt, G. H. 1992. Pregnancy and parturition. In: Textbook of Veterinary Physiology (Ed. J. G. Cunningham). W.B. Saunders, Philadelphia, pp. 457- 466.

Tsuruta, S. and I. Misztal. 2006. THRGIBBS1F90 for estimation of variance components with threshold and linear models. J. Dairy Sci. 89(Suppl. 1):15-18.

Varona, L., I. Misztal and J. K. Bertrand. 1999. Threshold-linear versus linear-linear analysis of birth weight and calving ease using an animal model: II Comparison of models. J. Anim. Sci. 77:2003-2007.

Żuk, B. 1989. Biometrics used (In polish Biometria stosowana), PWN Warszawa. 